\title{
Transaction Costs, the Opportunity Cost of Time and Inertia in Charitable Giving
}

Stephen Knowles ${ }^{1}$ and Maroš Servátka ${ }^{2}$

Address for correspondence:

Stephen Knowles

Department of Economics

University of Otago

PO Box 56

Dunedin

NEW ZEALAND

Email: stephen.knowles@otago.ac.nz

Telephone: 6434798350 


\title{
Transaction Costs, the Opportunity Cost of Time and Inertia in Charitable Giving
}

\author{
Stephen Knowles ${ }^{1}$ and Maroš Servátka²
}

1. Department of Economics, University of Otago, PO Box 56, Dunedin, New Zealand (email: stephen.knowles@otago.ac.nz); corresponding author

2. Department of Economics and Finance, University of Canterbury, Private Bag 4800, Christchurch 8140, New Zealand (maros.servatka@canterbury.ac.nz)

\begin{abstract}
We conduct a laboratory experiment to analyze the effect transactions costs and inertia have on charitable giving. We conjecture that transaction costs will have a greater effect on donations if the solicitation is received when the opportunity cost of time is high. Inertia could become a factor if people intend to give, but postpone making the payment until they have more time, and having postponed making the donation once, keep doing so. We find evidence of a transaction cost effect, with the size of this effect depending on the opportunity cost of time, but no statistically significant inertia effect.
\end{abstract}

Key words: charitable giving; dictator game; transaction costs; opportunity cost of time; inertia.

JEL codes: C91; D64

Acknowledgements: Earlier versions of the paper have been presented at the New Zealand Association of Economists Conference (Wellington, June 2013), the Australia New Zealand Experimental Economics Workshop (Brisbane, August 2013), the Science of Philanthropy Initiative Conference (Chicago, October 2013), the North American Experimental Economics Association Conference (Santa Cruz, October 2013) and in the University of Otago Seminar Programme (Dunedin, September 2013). We are grateful to participants for the many helpful comments received. Financial support was provided by the School of Business at the University of Otago and the College of Business and Economics at the University of Canterbury. 


\section{Transaction Costs, the Opportunity Cost of Time and Inertia in Charitable Giving}

"Never say I'll go tomorrow. When you get a chance to go fishing, go. If you wait until tomorrow, tomorrow will drag into next week and next week will drag into next month and next month into next year and some day it will be too late.” (Orman, 2004: attributed to T. Trueblood)

\section{Introduction}

This is not actually a paper about fishing, but about giving money to charity. The above quote, however, sums up what this paper is about if "go fishing" is replaced with "donate". Just as going fishing can be put off to another day, so can donating money to charity. This paper analyzes whether people are subject to such inertia with respect to charitable giving. In particular we ask whether some people intend to give money to charity, but simply never get around to doing so? For example, someone may read an email asking for a donation and is inclined to donate, but as she is busy preparing for a meeting decides to wait until after the meeting to click on the link to the charity's website and enter her credit card details. It is then possible, that having delayed making the donation once, she will do so again, until the opportunity to donate has passed.

Why do people postpone making their donations? Does the presence of transaction costs combined with a high opportunity cost of time at the moment of solicitation reduce donations? ${ }^{1}$ Both questions have important policy implications as finding ways to reduce transaction costs, and the potential for inertia, could increase donations to charity.

The three issues mentioned in the title of the current paper go hand in hand. We conjecture that inertia is likely to exist in the presence of transaction costs when two other conditions are satisfied simultaneously: (1) making a donation does not have to be made on the spot but can be postponed until later (which is usually the case with requests sent out by mail or email) and (2) the opportunity cost of donors' time at the moment they receive the request is high relative to the magnitude of transaction costs. The intuition is that if someone could transfer

\footnotetext{
${ }^{1}$ While nicely capturing inertia, there is no obvious role for transaction costs in the fishing example.
} 
money to a charity without this taking up any time and effort, there would be less reason to postpone the actual donation, once the decision to donate has been made. However, if potential donors are approached when they are busy (when their opportunity cost of time is high), even a small transaction cost may be enough to prevent them from donating immediately. Having postponed donating once, they may do so again, until the opportunity to donate has passed (i.e. inertia may result). A straight forward corollary is that if potential donors are approached when they are not busy, they might choose to make a donation right away even if it involves a transaction cost. Finally, if there is no opportunity to postpone the decision (e.g. as in street collections) there is no scope for inertia. We acknowledge that a "rational" donor would not suffer from inertia, but we conjecture that "behavioral" donors may do so. The behavior of rational donors would, however, be affected by transaction costs and by the interaction of transaction costs and the opportunity cost of time.

Inertia, as we interpret it, means situations in which people have the best intentions of doing something that they want to do (e.g. giving to charity), but because this does not have to be done immediately, putting it off, and then not getting around to doing so. This is similar to status quo bias, that is, doing nothing, or not changing one's previous decisions, e.g. choosing the default option in a retirement savings scheme or health insurance plan (Samuelson and Zeckhauser, 1988; Handel, 2013). Where inertia, as we define it, differs to status quo bias is that with inertia a conscious decision has been made to do something, but the transaction cost of doing so delays implementing the decision. ${ }^{2}$ Our interpretation of inertia also differs to procrastination and self-control problems due to inconsistent time preferences, where people find reasons to put off doing onerous tasks that generate immediate costs and future rewards and to willpower depletion (modelled by O’Donoghue and Rabin, 1999; Halevy, 2008; Harris and Laibson, 2013; Dekel and Lipman, 2011; Fudenberg and Levine, 2006; Ozdenoren, Salant, and Silverman, , 2012 and experimentally studied by Burger, Charness, and Lynham, 2011; Martinsson, Myrseth, and Wollbrant, 2012 among others). Inertia, by contrast, involves making a conscious decision to do something the person wants to do (e.g. donating money to charity because of the warm glow, or because the donor cares about the recipient's payoff), but not following through because it does not have to be done immediately. As the warm

\footnotetext{
${ }^{2}$ We acknowledge that Handel (2013) uses the term inertia to describe what we, and others (e.g. Samuleson and Zeckhauser, 1988) refer to as status quo bias.
} 
glow is likely received at the same time the donation is made, this suggests there is little scope for the separation of benefits and costs modelled by O’Donoghue and Rabin.,4

To study the impact of the opportunity cost of time, transaction costs and inertia on charitable giving, we nest our experimental manipulations in the Dictator Game. First implemented by Eckel and Grossman (1996), there now exists a large body of literature which uses Dictator Games to analyze giving to charity. Questions explored include the effects of rebates versus dollar-for-dollar matching of donations (see, for example, Eckel and Grossman, 2003; Davis, 2006), public recognition of donations (Karlan and McConnell, 2012), telling participants the charity will spend the money in poor countries (Brañas-Garza, 2006), providing information on why the country in which recipients live is poor (Etang, Fielding and Knowles, 2012), manipulating the perceived worthiness of recipients (Fong and Luttmer, 2011) and directing donations to an identifiable victim (Small, Loewenstein, and Slovic, 2007). However, in all of these studies subjects decide while in the laboratory whether to donate and then make that payment immediately. Hence, there is no possibility for inertia, as the payment cannot be delayed. There are also no transaction costs, as participants who choose not to donate do not get to leave the lab any earlier than those who do donate. However, in everyday life, giving money to a charity nearly always involves a transaction cost, for example, writing out a check and posting it, or visiting a website and taking the time to enter credit card details. Outside the laboratory there is also the possibility of inertia, as making the payment can often be put off to another time.

Testing our hypotheses requires modifying the standard Dictator Game to control for both the presence of transaction costs and the magnitude of the opportunity cost of time when the solicitation is received. We introduce a transaction cost by having subjects who wish to donate walk to another location on campus to make their donations. We refer to the amount of time taken to walk to the donation box as the "nominal transaction cost". The "effective transaction cost” depends on both the nominal transaction cost and the opportunity cost of

\footnotetext{
${ }^{3}$ In O'Donoghue and Rabin's model people have to undertake a costly activity once. With charitable giving, people have the choice of whether to donate or not.

${ }^{4}$ Breman (2011) conducts a field experiment and finds people already making regular monthly payments to a charity are more likely to agree to increase donations to the charity if the increase does not take place for some time. In this case, the warm glow would occur when the pledge to increase donations is made, but the cost is delayed, creating the potential for inconsistent time preferences. However, in most cases with charitable donations, there is no such pre-commitment and the warm glow likely occurs at the time the payment is actually made.
} 
time. To control for the opportunity cost of time at the time of the solicitation we develop a novel procedure that allows us to vary whether (i) subjects can donate immediately after the experimental session, but when they had expected to still be in the laboratory taking part in the experiment (i.e. the experimental session finished earlier than advertised), which serves as a proxy for a low opportunity cost of time, or (ii) whether the donation cannot be made until the following day, which rules out donating when we know the opportunity cost of time is low. If inertia exists, giving people more time to donate will reduce donations, especially if the opportunity cost of subjects' time when the solicitation is received is high. Hence, in the experiment we also vary the amount of time the subjects have to make a donation. In a field setting it is difficult to observe this opportunity cost at the time of the solicitation. However, in our laboratory experiment we are able to do so. Moreover, we can also compare donations in the presence of transaction costs against a baseline where transaction costs and inertia are both zero.

Our baseline treatment is the standard Dictator Game with a charity as a recipient, with no transaction costs or inertia. In various treatments we incorporate a transaction cost by requiring those who wish to make a donation to place the donation in a secure box located a short walk away. In some treatments subjects are able to make the donation at a time when we know the opportunity cost of time should be low; in other treatments subjects are only able to make a donation when the opportunity cost of time is likely higher, which varies the effective transaction cost.

In the first of these treatments subjects have one hour following the advertised completion time of the experimental session to make a donation. Crucial to our design is that the experimental sessions had been advertised to take one hour, but actually only took 35-40 minutes. Hence we know that subjects had time to walk to the box to make a donation during the time they had planned to be in the laboratory (hereafter "planned lab time”). As they were planning on participating in an experiment during this time, the opportunity cost of their time is low. We designed this treatment to serve as an analogue of, in everyday life, receiving a solicitation from a charity when you have the time to donate, if you choose to. The potential for inertia in this treatment is extremely low, so we interpret any difference between the baseline and this treatment as being due to transaction costs. 
In our second treatment we introduce the potential for inertia by giving subjects 25 hours following the advertised completion of the lab session to make a donation (i.e. they have 24 hours longer than in the first treatment). Any difference in donations between this treatment and the first treatment is likely due to inertia. However, as participants had the option in both treatments of donating promptly, at a time when their opportunity cost of time was low, the potential for inertia may still be reasonably low.

Our first two treatments were designed to analyze the case where people have the time to make a donation immediately following a solicitation. However, in everyday life requests from charities are often received when people are too busy to respond immediately. To mimic this situation in the lab we introduced a third treatment where subjects could only donate the next day; i.e. we ruled out the option of donating immediately, thereby creating an infinite opportunity cost of time at the moment of solicitation. As subjects who want to donate need to do so in their own time, rather than during planned lab time, it is likely that this represents a higher opportunity cost of their time, and hence a higher effective transaction cost, for most subjects compared to the first two treatments. Not allowing subjects to donate until the following day also creates a higher potential for inertia than in the second treatment.

Our fourth treatment is the same as the third, except that subjects are given an additional six days to make donations. That is they can make donations any day for the next week, starting the day following the experiment. As subjects have been given longer to donate than in the third treatment, the potential for inertia is higher in the fourth treatment. The effective transaction cost cannot be any higher in the fourth treatment than the third, as the payment options in the third treatment are a subset of those in the fourth, so if donations are lower in the fourth treatment, this would be evidence of inertia.

When we ran the experiment we found that average donations were sufficiently low in the third treatment that it would be difficult to observe a statistically significant lower level of donations in the fourth treatment. Hence, we postponed running the fourth treatment and recalibrated the design to increase average donations across treatments, and then conducted both the third and fourth treatments using the new procedures. This second study took place three months after the first study. Hence Study One includes the baseline and first three treatments, with Study Two including the third (representing a new baseline) and fourth treatments. The main focus of Study One is on the role of transaction costs and how these interact with the opportunity cost of time. Study One sheds some light on the conditions 
under which inertia is likely to exist, but it is Study Two that speaks more directly to whether inertia is likely to reduce donations to charity.

The remainder of the paper is structured as follows. The next section reviews the relevant literature, sections 3 and 4 respectively present the experimental design and results of Study One while sections 5 and 6 present the design and results of Study Two. Section 7 concludes.

\section{Literature Review}

Field experiments have been used to analyze a range of issues with respect to charitable giving; for example, the effect of lead donations (List and Lucking-Reiley, 2002), lotteries versus voluntary contributions (Landry, Lange, List, Price, and Rupp, 2006), whether receiving a large number of requests irritates potential donors (Van Diepen, Donkers, and Franses, 2009), reasons as to why donors support multiple charities (Null, 2011; de Oliveira, Croson, and Eckel, 2011) and the correlation between giving and socio-demographic characteristics (Bekkers, 2007). There are also two field experiments on the effect of transaction costs in the context of charitable giving: Huck and Rasul (2010) and Meer and Rigbi (2013). However, these studies are unable to control for the opportunity cost of time at the time the solicitation is received.

Huck and Rasul (2010) separate transaction costs into two components: ex-ante transaction costs and ex-post transaction costs. Ex-ante transaction costs are defined as the time taken to consider a request for a charitable donation (e.g. read a letter or brochure) and the time taken to make a decision as to whether to give. Ex-post transaction costs are defined as the costs associated with making a donation (e.g. writing a check and posting it). ${ }^{5}$ Huck and Rasul's paper involves two separate field experiments. In the first experiment ("the reminder experiment”) letters are sent to potential donors asking for donations for a youth project run by the Bavarian Opera House. ${ }^{6}$ Six weeks following the original letter, a reminder letter was sent out to 2/3 of those who had not yet donated. Huck and Rasul argue that there are only two reasons why someone who did not respond to the initial appeal may have responded to

\footnotetext{
${ }^{5}$ In our setup, subjects incur ex-ante transactions costs in the lab (reading/listening to the instructions and likely also making a decision) whereas ex-post transaction costs are incurred by having to walk to the donation box.

${ }^{6}$ To test the external validity of their result a similar study was conducted using the Royal Opera House in Covent Garden.
} 
the reminder: (1) preferences have altered, or (2) the reminder triggered a new draw from the same distribution of transaction costs (e.g. perhaps they were not as busy when the reminder letter arrived). As the reminder letter provided no new information about the appeal, and the authors claim it is unlikely anyone's preferences would have changed in a short period of time, any response to the second letter is interpreted as being due to lower transaction costs at the time the second letter was received. There were a significant number of responses to the reminder letter, which they argue implies the presence of transaction costs. The idea that people face different transaction costs at different times is consistent with our contention that when people are asked to make a donation they will sometimes have time to do so immediately, and sometimes will not. If they do not have time now, and postpone making the donation, it is possible they will never get around to donating.

In Huck and Rasul's second experiment, a request letter is sent out for a separate fund raising project for the Bavarian Opera House. Different treatments provide different payment options (a bank transfer in one treatment versus a pre-filled bank transfer form and paying by credit card over the phone in another treatment) to test for the effect of ex-post transaction costs and differing levels of information on the envelope the letter is delivered in to test for the effect of ex-ante transaction costs. Evidence is found that ex-post transaction costs affect response rates, but not mean donations.

Meer and Rigbi (2013) analyze transactions costs in the context of whether people donating money to entrepreneurs in developing countries, through the Kiva online platform, are more likely to donate money to projects where the information posted about the project is in the donor's own language. They argue that donors having to translate the information themselves represents a transaction cost. This study is a randomized natural experiment, as for a period of time in 2009 Kiva volunteers translated a proportion of the non-English-language project profiles into English, with it being determined at random which profiles were translated. Meer and Rigbi find evidence of a transaction cost effect, for donors living in a country where English is the main language. Note, however, that Meer and Rigbi are not so much focusing on the effect of transaction costs on the decision of whether to donate or not (as those using the website have incurred a fixed cost of signing up, and the fact that they are browsing the website indicates a desire to donate). Instead they are focusing on the effect of transaction costs on the decision of who to donate to, conditional on having an interest in making a donation. 
We are unaware of any existing studies (either field or lab experiments) which analyze the role of inertia with respect to charitable giving. However, there is a literature on the role of inertia more generally. Choi, Laibson, Madrian, and Metrick (2002) compare data from an online survey of workers employed by a large US company, which asked if workers planned to increase contributions to their company’s 401(k) savings scheme, with the company's administrative records on employees' actual contributions. They find that only 14 percent of those who said they planned to increase their contributions in the next few months did so, leading them to conclude that "respondents overwhelmingly do not follow through on their good intentions.” (p.74). Leventhal, Singer and Jones (1965) provide Yale students with information about tetanus and then ask them if they plan to get inoculated. The majority of students said they planned to get inoculated, but only a small minority did.

These existing studies on inertia test for an inertia effect by comparing peoples' intentions with their subsequent actions (e.g. do people who say they plan to get inoculated do so). Our approach for testing for inertia is somewhat different, in that we focus on whether giving people more time to donate reduces donations. We adopt this approach for two reasons. The first is we suspect that getting subjects to state their intentions, albeit anonymously, to the researchers may actually reduce the amount of inertia. That is, having made a written commitment to donate subjects may be more likely to do so. As most everyday solicitation methods do not ask for a commitment in this way, we also do not ask for such a commitment in case this masks the inertia effect we are trying to identify. The second reason for our approach is that, from a policy perspective, we think it is an interesting question to consider whether it is possible to give people too much time to donate.

To the best of our knowledge, the question of whether inertia affects charitable giving has not been analyzed in the literature. However, as discussed above, there is evidence that inertia affects other types of behavior. We suggest that giving to charity may be similar. Many people, upon receiving requests from a charity, may intend to make a donation, but they simply never get around to doing so. There are two field experiments analyzing the effect of transaction costs on charitable giving, and these make a valuable contribution to the literature. We see analyzing transaction costs using a laboratory experiment as a useful complement to these existing studies. Our experimental design allows us to control for the opportunity cost of time of subjects and to introduce transaction costs, which are both crucial when analyzing inertia. In our setting we are able to implement treatments where we know subjects have time on their hands to donate immediately upon receiving the solicitation, and 
treatments where we rule out the possibility of donating immediately (the analogue of the everyday life situation of receiving a request when you are too busy to donate now).

\section{Study One Experimental Design and Procedures}

The experiment took place in the New Zealand Experimental Economics Laboratory (NZEEL) at the University of Canterbury, with 246 undergraduate students serving as subjects. The participants were selected randomly from the NZEEL database using the ORSEE recruitment system (Greiner, 2004). The sessions were advertised as a 'Life as a Student' survey for which the participants would receive $\$ 20$, followed by a short decisionmaking task. ${ }^{7}$ We advertised that a session might take up to one hour, however, each session lasted only 35-40 minutes. As discussed previously, this was to ensure that in some treatments subjects would have sufficient time to drop off their donations in a different location on campus before attending other activities they might have scheduled right after the experiment.

Upon entering the laboratory all participants were seated at cubicles. After reading through the survey instructions, we handed out the survey forms in large manila envelopes. The subjects were given 10 minutes to complete the survey, after which they were asked to place the forms back into the manila envelope to protect their anonymity. ${ }^{8}$ Since we were not interested in analyzing survey responses, and wanted to create a perception of the highest level of anonymity, the survey forms were not marked in any way.

After the completed surveys were collected in, we handed out instructions for the decisionmaking task. The instructions informed the subjects that we were going to hand out white envelopes containing their \$20 payment for filling out the survey. We asked the subjects to open the envelope and confirm it contained $\$ 20$, since we needed them to sign a receipt for accounting purposes before they left the lab. Subjects were then given an opportunity to donate some, or all, of their \$20 payment to World Vision New Zealand, who are a registered

\footnotetext{
${ }^{7}$ The adult minimum wage in New Zealand at the time of the experiment was 13.75 NZD per hour. 1 NZD = 0.82 USD at the time of the experiment.

${ }^{8}$ The survey questions are provided in the appendix.
} 
charity doing development work in poor countries overseas. ${ }^{9}$ We informed them that any money they chose to donate would be matched by us dollar for dollar and we would forward all money directly to World Vision. The white envelope contained a \$10 note, a \$5 note, two $\$ 2$ coins and a $\$ 1$ coin, so it was possible to donate any whole dollar amount, between $\$ 0$ and $\$ 20$. We reminded the subjects that they were under no obligation to donate any money unless they wished to do so.

Subjects randomly selected a blue envelope from a box carried around the lab by one of the experimenters. The envelope contained a blue form with a space to indicate how much money, if any, the subjects wished to give to World Vision, and how much money this meant World Vision would receive once we matched their donation dollar for dollar. Requiring subjects to write down both the amount of their donation, and how much World Vision would receive, enabled us to verify that subjects understood the nature of the matching subsidy. We explained that for audit reasons we would only be able to match any donation they made if we had a written record of what had been donated, hence the need to complete the blue donation form. The matching subsidy was particularly important, as we wanted to create an incentive for participants to give us the money to pass on to the charity, rather than them sending it to the charity themselves, or donating to a different charity following the experiment. The way the actual donations were made, including when the blue transfer form was completed, varied across treatments and is described below.

The experiment was run under a double-blind social distance protocol to make subject decisions completely anonymous and thus constant across treatments. This was crucial since we wanted to ensure that the subjects did not perceive their decisions to be more anonymous in treatments where donations were dropped in a box in a different location on the university campus, as opposed to in a box right outside the lab. Neither subjects' names nor their student ID numbers appeared on any form that recorded their decisions. The only identifying mark was an alpha-numeric code on the donation forms and envelopes. We explained to participants that since they randomly picked an envelope from a box, we had no way of knowing who had been assigned which code. In an attempt to minimize the chances that the subjects' donation decisions would be influenced by their peers at the end of the session we asked the subjects one at a time to come up to a room at the back of the laboratory and sign a receipt for $\$ 20$ for

\footnotetext{
${ }^{9}$ We did not provide any other information about the charity. Note, however, that World Vision is a very wellknown charity in New Zealand, especially among younger people as many secondary schools participate in World Vision's annual 40-hour famine.
} 
completing the survey. This ensured that they left the lab at 30-40 second intervals. We asked them not to wait around outside the lab, and checked to make sure that they did not.

In order to analyze the effects of transaction costs and inertia on charitable giving we implemented four different treatments, using an across-subjects design. What varied across the different treatments was when and where any donation was made. In Baseline (B) participants placed their donation, and the blue transfer form, in the blue envelope and placed the envelope in a box outside the laboratory immediately following the experimental session. Subjects were told to put any money they had chosen to keep in their pocket or bag. Subjects who did not wish to make a donation also put the blue envelope in the box, but without any money, which kept anonymous whether subjects made a donation or not. Making a donation at the time of the experiment is the standard procedure in Dictator Games with a charity acting as the recipient. In this treatment there is no transaction cost and no possibility for inertia, which allows us to nest our further treatments.

In the One Hour $(1 \mathrm{H})$ treatment, participants wishing to make a donation had to place the blue envelope, containing their donation and the blue donation form, in a secure box elsewhere on the university campus, and had one hour (following the advertised completion time of the survey) to do so. The walking time from the lab to the donation box is approximately 5 minutes. The laboratory is located on the outskirts of the campus, with the box being located in a more central part of the campus. Hence for subjects planning on walking back towards the centre of the campus following the experimental session, the marginal amount of time to walk to the box would be less than 5 minutes, and for participants planning on heading in the opposite direction following the session it would be more than 5 minutes. Hence, the nominal transaction cost might vary across participants. This is also true in everyday life where some participants will write a check and post it, others will pay online, and for those paying online internet speeds may differ. ${ }^{10}$ In order to ensure that the secure

\footnotetext{
${ }^{10}$ Depending on how much marginal time subjects took to make donations, the transaction cost in our laboratory experiment may be slightly higher than the time taken to make a donation in everyday life. However, the difference does not seem to be that great. To check this, we made a small number of donations to charities online, and noted the amount of time this took. Each donation was in response to an email (or having already looked up the charity's web site) so making the donation only required clicking on a link in an email, then entering credit card details and any other information requested by the charity. In each case, we had a credit card already at hand. The shortest time taken to make a donation was 1.5 minutes, with the longest being 3.5 minutes. The average time taken to donate was 2.25 minutes. In one case, not included in these summary statistics as it was an unusual case, making the donation took approximately 10 minutes as when the researcher visited a website he had previously registered for, he had to change the expiry date on his credit card. It took some time to figure out how to do this.
} 
box was easy to find, participants in $1 \mathrm{H}$, and all subsequent treatments, were provided with a map showing the location of the box. On the map we included the time by which they needed to make a donation, if they wished to do so. In this (and also in the next) treatment, subjects were asked to open the blue envelope, while in the lab, and check that it contained the transfer form and map, but were asked not to fill in the transfer form until they had left the lab. $^{11}$

The $1 \mathrm{H}$ treatment introduces a transaction cost: the time taken to walk to the donation box. ${ }^{12}$ As participants had been told the experimental session would take up to 60 minutes, and the last participant left within 35-40 minutes, we know that participants had plenty of time to walk to the box before the 60 minutes of planned lab time was up. In other words, the nominal transaction cost was being incurred during time for which all subjects should have had no previous plans. This is not to say the opportunity cost of walking to the box was zero, as they could, when leaving the lab, choose to do something else with the time, but the opportunity cost would not likely be high.

The potential for inertia is extremely low in the $1 H$ treatment as there is very little scope for postponing making a donation. The only possible source of inertia would be for someone to decide to make a donation in 60 minutes time, rather than immediately after leaving the lab, and then not get around to doing so. Hence, we interpret any difference between $B$ and $1 H$ as being due to transaction costs.

Our One Day (1D) treatment is identical to $1 \mathrm{H}$, except that subjects were given 25 hours to make a donation. This treatment includes the transaction cost and, as making a donation can be delayed until the following day, this treatment introduces potential for inertia. That is, subjects could postpone making their donation until the next day, but then not actually donate. This treatment enables us to observe, by clearing the box at regular intervals, the

\footnotetext{
${ }^{11}$ Subjects were told that if they needed a pen to fill in the form, after leaving the lab, to feel free to take the pen we had given them to complete the survey.

${ }^{12}$ Note that there are alternative ways of introducing a transaction cost in our design, for example by having subjects who wish to donate fill out a long transfer form. However, while filling in a lengthy form requires some effort, if the form was filled in during lab time and the choice is between filling in the form and sitting doing nothing, subjects would likely not consider that filling in the form involved a significant cost. Alternatively, letting those who chose not to donate to leave the laboratory, while others are filling in the transfer form, would compromise the double-blind protocol. Finally, since we are also testing for inertia, we have to allow subjects to make their donation at a later time, meaning they will incur the opportunity cost of time of walking to the box anyway, so having the opportunity cost of walking to the box is unavoidable.
} 
proportion of people who choose to make their donation promptly following the laboratory session.

In our first two treatments ( $1 \mathrm{D}$ and $1 \mathrm{H})$, subjects were able to make their donation immediately upon leaving the laboratory, during planned lab time. As discussed previously, this is analogous to receiving a request from a charity when you have time on your hands to donate immediately (when your opportunity cost of time is low). To simulate the everyday life situation where a request is received at a time when the opportunity cost of time is high, our Next Day (ND) treatment only allowed for donations to be made (in the same box located elsewhere on campus) between $8 \mathrm{am}$ and $5 \mathrm{pm}$ the following day. ${ }^{13}$ This represents a higher effective transaction cost compared to the other treatments, as subjects do not have the option of making the donation in planned lab time. ${ }^{14,15}$ By not allowing donations until the following day, this treatment also allows for inertia, in the sense that participants might intend to donate the following day, but not get around to doing so. In fact, as we ruled out donating immediately, the potential for inertia is higher than in any of our previous treatments.

The different experimental treatments are summarized in Table One. There is no transaction cost or inertia in the Baseline. $1 \mathrm{H}$ introduces a nominal transaction cost but no inertia, with $1 D$ including both a nominal transaction cost and inertia. In both $1 H$ and $1 D$ the donation can be made during planned lab time, so the opportunity cost of time is low, at the time the solicitation is received. $N D$ has both a nominal transaction cost and inertia, but the donation cannot be made in planned lab time, or even the same day, representing a high opportunity cost of time. As the effective transaction cost depends both on whether there is a nominal

\footnotetext{
${ }^{13}$ Outside of these times the building, where the secure box was located, is locked, so is not accessible to undergraduate students. This time restriction was announced to participants in all treatments where it was relevant.

${ }^{14}$ An alternative way of creating a high opportunity cost of time would have been to have a treatment where subjects remained in the lab for the full hour the session was advertised for. However, we would not have known whether subjects were busy or not when they left the lab. If subjects were not busy when they left the lab after an hour, this treatment would actually be very similar to $1 D$. The $N D$ treatment, by contrast, imposes an infinite opportunity cost of time when the solicitation is made, giving a clean comparison with $1 D$, where we knew the opportunity cost of time was low.

${ }^{15}$ Note that subjects were told not to open the blue envelope containing the transfer form until they had left the lab. However, they were shown a copy of the map, which noted the time a donation could be made, and the transfer form did not include any information that was not included in the written instructions.
} 
transaction cost and whether the donation can be made during planned lab time, the effective transaction cost is highest in ND. The potential for inertia is also highest in ND.

Table 1. Summary of Experimental Treatments

\begin{tabular}{|c|c|c|c|c|}
\hline & $\begin{array}{c}\text { Nominal } \\
\text { Transaction } \\
\text { Cost }\end{array}$ & $\begin{array}{c}\text { Opportunity } \\
\text { Cost of Time } \\
\text { (when request is } \\
\text { received) }\end{array}$ & $\begin{array}{c}\text { Effective } \\
\text { Transaction } \\
\text { Cost }\end{array}$ & Inertia \\
\hline Baseline & Zero & $\mathrm{n} / \mathrm{a}$ & Zero & Zero \\
\hline $1 H$ & Yes & Low & Yes & Extremely Low \\
\hline $1 D$ & Yes & Low & Yes & Yes \\
\hline$N D$ & Yes & Infinite & $\begin{array}{c}\text { Yes; higher than } \\
\text { 1D and IH }\end{array}$ & $\begin{array}{c}\text { Yes; higher than } \\
1 \mathrm{D} \text { and } 1 \mathrm{H}\end{array}$ \\
\hline
\end{tabular}

Our conjectures and testable hypotheses can be summarized as follows.

Conjecture 1: introducing a transaction cost (but still requiring donations to be made promptly ruling out inertia) will reduce donations.

Hypothesis 1: $1 H<B$ (and all other treatments).

Conjecture 2: giving more time to donate, when the opportunity cost of time is low, will not introduce inertia and therefore not reduce donations.

Hypothesis 2: $1 \mathrm{H}=1 \mathrm{D}$

Hypothesis 2 tests the effect of giving subjects more time to donate, but keeping the opportunity cost of time low when the request is received. While giving more time to donate could potentially introduce inertia (condition 1 presented in the introduction), condition 2, which specifies that inertia requires high opportunity cost of time, is not satisfied. Since we conjecture that both conditions have to be satisfied simultaneously in order for inertia to be found, we not expect to observe a difference between $1 H$ and $1 D$. 
Conjecture 3: The potential for inertia, and the effective transaction cost, will be higher if the request is received at a time when the opportunity cost of time is high (and in the presence of transaction costs).

\section{Hypothesis 3: $N D<1 D$}

Hypothesis 3 tests the effect of giving people more time to donate (hence introducing inertia) but ruling out donating immediately (i.e. the opportunity cost of time is infinite when the request is received). Lower donations in $N D$ could be due to the higher effective transaction cost (which is due to the higher opportunity cost of time) or to the higher potential for inertia.

Conjecture 4: If the opportunity cost of time is low when the request is received, we would expect most subjects who choose to donate to do so promptly minimizing the potential for inertia.

Hypothesis 4: in $1 D$ the majority of donations will be made promptly.

Hypothesis 4 tests whether people will tend to donate promptly if, at the time the solicitation is received, their opportunity cost of time is low.

\section{Study One Results}

Summary statistics for each treatment are reported in Table 2, with Figure 1 depicting the results graphically. The modal donation in all treatments is to give nothing. The mean donation in $B$ is $\$ 2.48$ (12.4\% of the subjects' endowment), ${ }^{16}$ with over half (58\%) of subjects giving a positive amount of money to the charity. ${ }^{17}$ Donations are higher in $B$ than in

\footnotetext{
${ }^{16}$ Our mean donation of $12 \%$ in Baseline is lower than in some other Dictator Games where the recipient is a charity, but is the same as in Reinstein and Reiner's (2012) performance/cash treatment. Like our Baseline treatment, in their performance/cash treatment there is a double-blind protocol, subjects were not paid a show-up fee, they had to earn their endowments and were paid prior to making a decision as to how much to donate. However, one difference between our study and Reinstein and Reiner's is that we include a matching subsidy.

${ }^{17}$ Recall that subjects were paid a $\$ 10$ note, a $\$ 5$ note, two $\$ 2$ coins and a $\$ 1$ coin. It is, therefore, tempting to expect a significant number of $\$ 5$ donations, from those happy to get rid of the coins, but wanting to keep the notes. However, across the different treatments there were three people who gave $\$ 5$, one who gave $\$ 10$ and one who gave $\$ 15$, who donated the notes and kept the coins. By contrast, in the $N D$ treatment, there were two subjects who used the opportunity to put some of their own loose change (coins smaller than \$1) in the envelope, and keep the larger denomination coins and the notes, which we had paid them, for themselves.
} 
any of the treatments, and a casual inspection of Figure 1 suggests this may be due in large part to the lower number of small donations (those between \$1 and \$4) made in the various treatments compared to in $B$. This is consistent with average donations, conditional on making a donation, being lowest in $B$.

Table 2: Summary Statistics for Study One

\begin{tabular}{|l|c|c|c|c|}
\hline Treatment & $\begin{array}{c}\text { Baseline } \\
\text { (B) }\end{array}$ & $\begin{array}{c}\text { One } \\
\text { Hour } \\
(\mathbf{1 H})\end{array}$ & $\begin{array}{c}\text { One Day } \\
\text { (1D) }\end{array}$ & $\begin{array}{c}\text { Next Day } \\
\text { (ND) }\end{array}$ \\
\hline \multicolumn{5}{|c|}{ Panel A: All Data } \\
\hline Number of observations & 60 & 58 & 61 & 67 \\
\hline Average donation & 2.48 & 1.43 & 1.72 & 1.20 \\
\hline Median donation & 2 & 0 & 0 & 0 \\
\hline Standard deviation & 3.52 & 3.41 & 5.33 & 4.37 \\
\hline & Panel B: Intensive Margin & \\
\hline $\begin{array}{l}\text { Number of positive } \\
\text { donations }\end{array}$ & $\begin{array}{c}35 \\
(58.3 \%)\end{array}$ & $\begin{array}{c}14 \\
(24.1 \%)\end{array}$ & $\begin{array}{c}(23.0 \%) \\
(14\end{array}$ \\
\hline $\begin{array}{l}\text { Average donation } \\
\text { conditional on giving }\end{array}$ & 4.26 & 5.93 & 7.50 & 11.36 \\
\hline $\begin{array}{l}\text { Median donation } \\
\text { conditional on giving }\end{array}$ & 3 & 5 & 5 & 10 \\
\hline $\begin{array}{l}\text { Standard deviation } \\
\text { conditional on giving }\end{array}$ & 3.71 & 4.73 & 6.28 & 8.49 \\
\hline
\end{tabular}




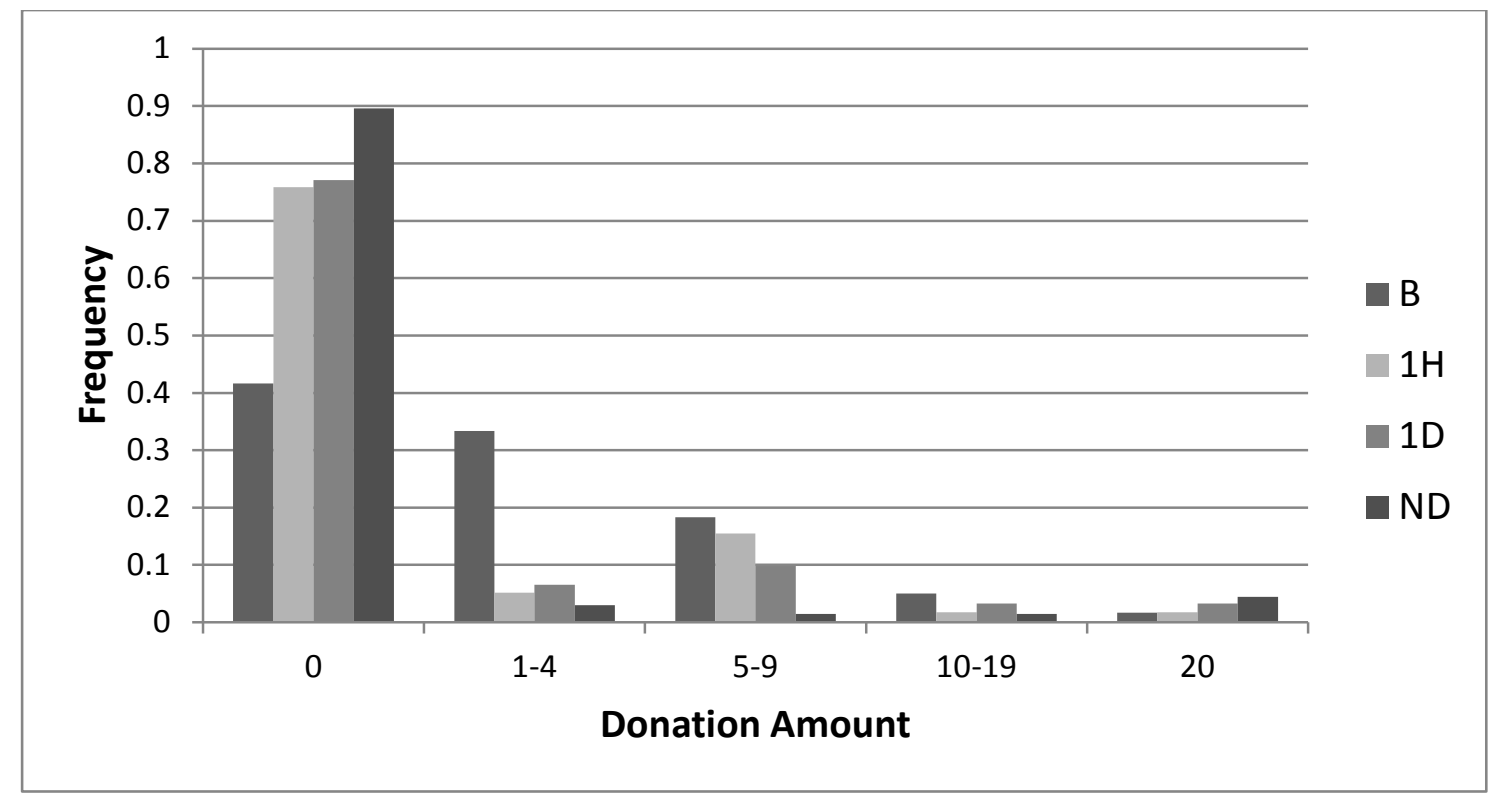

Figure 1: Frequency of Different Levels of Donations

Table 3 provides more detail on the proportions of total donations in each treatment accounted for by small (\$1-\$4) and large (\$5 or greater) donations. In $B$, 33\% of subjects donate between $\$ 1$ and $\$ 4$, but this falls to single figure percentages in all the treatments. ${ }^{18}$ Of the $\$ 2.48$ average donation in $B, \$ 0.68$ of this is made up of small donations, with the remaining \$1.80 made up of large donations. The proportion of small donations is much lower in all remaining treatments.

\footnotetext{
${ }^{18}$ Fisher's Exact Test reports a significant difference in the proportion of small and large donations between $B$ and all the other treatments ( $\mathrm{p}=0.000$ in all three cases.)
} 
Table 3: Small and Large Donations

\begin{tabular}{|l|c|c|c|c|}
\hline Treatment & $\begin{array}{c}\text { Baseline } \\
\text { (B) }\end{array}$ & $\begin{array}{c}\text { One Hour } \\
(\mathbf{1 H})\end{array}$ & $\begin{array}{c}\text { One Day } \\
(\mathbf{1 D})\end{array}$ & $\begin{array}{c}\text { Next Day } \\
\text { (ND) }\end{array}$ \\
\hline \multicolumn{5}{|c|}{} \\
\hline Number of observations (N) & 60 & 58 & 61 & 67 \\
\hline $\begin{array}{l}\text { Number of small donations } \\
(\$ 1-\$ 4)\end{array}$ & 20 & 3 & 4 & 2 \\
$(33.3 \%)$ & $(5.2 \%)$ & $(6.6 \%)$ & $(3.0 \%)$ \\
\hline \$ value of small donations & 41 & 6 & 10 & 4.50 \\
\hline \$ value of small donations / N & 0.68 & 0.10 & 0.16 & 0.07 \\
\hline $\begin{array}{l}\text { Number of large donations } \\
\text { (\$5 or more) }\end{array}$ & 15 & 11 & 10 & 5 \\
\hline \$ value of large donations & $125.0 \%)$ & $(19.0 \%)$ & $(16.4 \%)$ & $(7.5 \%)$ \\
\hline \$ value of large donations / N & 1.80 & 1.32 & 1.56 & 1.12 \\
\hline Average donation & 2.48 & 1.43 & 1.72 & 1.20 \\
\hline
\end{tabular}

Table 4 presents formal statistical tests for whether the differences across treatments are statistically significant. We report standard t-tests for the difference between means, but as the data are not normally distributed we focus more on the results for a non-parametric Wilcoxon Rank Sum Test of the null hypothesis that the two distributions are identical. We also report Fisher's Exact Test for the proportion of positive donations, to test if the number of positive donations is statistically significantly different across treatments. The only pairwise comparison of treatments where the differences are not statistically significant is between $1 \mathrm{H}$ and $1 \mathrm{D}$. For the intensive margin, the average donation conditional on donating is statistically significantly lower in $B$ compared to all other treatments, but none of the other pairwise comparisons are statistically significant (which is likely due to the small number of positive donations in many of these treatments). 
Table 4: Significance Tests for Differences across Treatments

\begin{tabular}{|l|c|c|c|}
\hline Data & Means t-test & $\begin{array}{c}\text { Wilcoxon Rank- } \\
\text { Sum Test }\end{array}$ & $\begin{array}{c}\text { Fisher's Exact Test } \\
\text { for Proportion of } \\
\text { Positive Donations }\end{array}$ \\
\hline \multicolumn{4}{|c|}{ Panel A: Mean Donations (All Data) } \\
\hline B vs. 1H & $1.65(0.102)$ & $-3.15(0.002)$ & $(0.000)$ \\
\hline B vs. 1D & $1.06(0.290)$ & $-3.25(0.001)$ & $(0.000)$ \\
\hline B vs. ND & $1.86(0.066)$ & $-5.20(0.000)$ & $(0.000)$ \\
\hline 1H vs. 1D & $-0.41(0.684)$ & $-0.10(0.920)$ & $(0.055)$ \\
\hline 1H v ND & $0.35(0.725)$ & $-1.91(0.056)$ & $(0.093)$ \\
\hline 1D v ND & $0.70(0.487)$ & $-1.82(0.070)$ & \\
\hline \multicolumn{1}{|c|}{ Panel B: Intensive Margin (Mean Donation Conditional on Donating) } \\
\hline
\end{tabular}

All reported tests are 2-sided.

Our four key results are summarized below.

Result 1 (based on hypothesis 1): Transaction costs reduce donations.

Support for Result 1: Introducing a relatively small nominal transaction cost (requiring subjects to take a short walk in order to make a donation), but without introducing any possibility for inertia, reduced average donations from $\$ 2.48$ in the baseline to $\$ 1.43$ in $1 \mathrm{H}$. This difference, which is significantly different ( $\mathrm{p}$-value $=0.002)$, represents a decrease in donations of 42 percent. The Fisher's Exact Test, reported in the first three rows of Table 4, suggests there are significantly ( $\mathrm{p}$-value $=0.000$ ) more positive donations in $B$ than in any of the treatments. A large part of this reduction in donations is due to fewer small donations (in the \$1-\$4 range) being made once a transaction cost has been introduced. 
Result 2 (based on hypothesis 2): There is no evidence of inertia when the request is received at a time when the opportunity cost of time is low.

Support for Result 2: All three tests reported in the fourth row of Table 4 find no statistically significant difference in giving between $1 H$ and $1 D$. Failing to find a significant difference between these treatments is consistent with our conjecture that inertia is less likely to exist if the solicitation is received at a time when the opportunity cost of time is low. However, another possibility, which we cannot rule out, is that there may be subjects for whom the nominal transaction cost is lower in $1 D$ if they have a class near the box the following day. If this is the case, then this would mean the effective transaction cost is lower in $1 D$, but the potential for inertia higher, with the two effects potentially cancelling out.

Result 3 (based on hypothesis 3): Nominal transaction costs have a bigger impact when the solicitation is received at a time when the donation cannot be made immediately.

Support for Result 3: Average donations fall from $\$ 1.72$ in $1 D$ (where the donation can be made immediately, at a time when the opportunity cost of time is known to be low, or at any other time in the following 25 hours) to $\$ 1.20$ in ND (where the donation cannot be made until the next day). This difference is significantly different (p-value $=0.070)$ and represents a reduction in donations of 30 percent. There is a significantly higher proportion of positive donations in $1 D$ than in $N D$ (p-value $=0.093)$.

There are two possible reasons for why nominal transaction costs have a bigger impact when the donation request is received at a time when the donation cannot be made immediately. The first is that the transaction cost is higher (as the opportunity cost of time is higher) and the second is that delaying making the donation introduces the potential for inertia ("I do not have to make a donation now, so will do so tomorrow”). As our experiment was not designed to distinguish between these explanations, we leave this issue for future research. Note, however, that from a policy perspective, the important point is that donations are lower, if the solicitation is received when the potential donor's opportunity cost of time is high.

Result 4 (based on hypothesis 4): Given the option of donating promptly or delaying payment most subjects choose to donate promptly.

Support for Result 4: As we discretely cleared the box at regular intervals, our design enabled us to observe what proportion of participants chose to donate promptly, when we knew their 
opportunity cost of time was low, rather than delay making the donation until the following day. In $1 D$ subjects could make their donation any time in the 25 hours following the experiment. One interesting result from this treatment is that of the 14 subjects who gave a positive amount, 12 did so that day, with only 2 making a donation the following day. Of the two people donating the following day, one donated the full \$20 and the other donated \$10. This is an important result, as it is provides some confirmation that subjects really did perceive the opportunity cost of their time to be low immediately following the lab session, giving us confidence that our method for controlling the opportunity cost of time, at the time of the solicitation, is valid.

\section{Implications of Study One Results}

Our results from Study One suggest a number of important findings with policy implications for charities. The first is that introducing a transaction cost reduces donations, but this comes about largely as a result of transaction costs reducing the number of smaller donations. If the charity receiving the money also faces a transaction cost in processing donations, this reduction in smaller donations may not be a bad thing from the charity’s perspective. However, if there is a very low marginal transaction cost faced by the charity, lowering the transaction cost for the donor would be desirable. One example of a fund raising effort with low transaction costs for both the donor and charity is street collections where volunteers stand on the street with a container asking passers-by for a donation. Another example is charities advertising that if a text message is sent to a certain number, that a specified donation will be made to the charity and the amount be automatically added to the donor's

phone bill. Taking our results at face value would suggest such fund raising mechanisms are a good way of targeting those who would be happy to make a small donation, but would be put off by even a small transaction cost. Smith (2012) reports that \$43 million was raised in the US in response to the Haiti earthquake, as a result of advertisements encouraging people to send a text message to make a $\$ 10$ donation. Based on a survey of a sample of those who donated, Smith finds that 50\% donated immediately upon learning about the campaign, with an additional 23\% donating on the same day. This is consistent with donating promptly in response to low transaction costs. Increased use of the push-pay app, which is available for use on smart phones, would also greatly reduce transaction costs, as the web site for the app claims that, once registered, users can make payments in only ten seconds. Our results would suggest this should increase donations to charity. 
Our results also suggest that donations will be higher if people receive a request from a charity at a time when their opportunity cost of time is low. This has important implications for charities as it implies donations will be higher if they can catch potential donors when they have time on their hands to donate, if they choose to do so. Perhaps street collectors could position themselves near bus stops, and other places where people with time on their hands are likely to be congregating. Our results also have some welfare implications. We assume that the people who gave in the baseline did so because this increased their utility, either due to a warm glow from giving, or because they derive utility from the consumption of others (in this case the people overseas who benefit from the work of World Vision). It follows that making it easier for people to donate (by reducing transaction costs and soliciting people when their opportunity cost of time is low) will be welfare improving.

\section{Study Two Experimental Design and Procedures}

Study Two introduces a treatment which gives subjects one week to make a donation, starting at 8am the day following the experimental session. We refer to this treatment as the Next Day all Week (NDW-2) $)^{19}$ treatment. Comparing the $N D-2$ with $N D W-2$ treatments enables us to test whether giving subjects more time to donate reduces donations. As the effective transaction cost can be no higher in $N D W-2$ than in $N D-2$ (as the options for when to donate in $N D$-2 are a subset of those in $N D W-2$ ) finding a lower level of donations in $N D W-2$ would be evidence of an inertia effect.

As mentioned earlier, the low level of donations in the $N D$ treatment in Study One raised the concern that it would be difficult to observe a statistically significant difference between the $N D$ and $N D W$ treatments, hence we did not run the $N D W$ treatment in Study One. In Study Two, conducted three months after Study One at NZEEL with new subjects, we changed the experimental design in two key ways in an attempt to increase average donations for both the $N D-2$ and $N D W-2$ treatments. Comparing $N D-2$ with $N D W-2$ tests for the presence of an inertia effect, when the solicitation is received at a time when the opportunity cost of time is high. Hence, the key focus of Study Two is to analyze whether giving subjects more time to donate reduces donations, if the opportunity cost of time is high at the time of the solicitation.

\footnotetext{
19 “-2” indicates that Study Two procedures were used.
} 
The first change to the experimental design was to give subjects their endowment as a windfall gain, rather than getting them to earn it. The lab session was advertised as being a decision-making task lasting 30 minutes, for which subjects would be paid a \$10 show-up fee. Having been paid their show-up fee, participants were given an additional payment of $\$ 10$ and invited to donate some or all of the additional payment (which was paid to them as one \$5 note, two \$2 coins and one \$1 coin) to World Vision. Hence, the additional \$10 represented a windfall gain. A number of studies find that subjects will be more generous in Dictator Games if their endowment is a windfall gain (see, for example, Cherry, Frykblom and Shogren 2002; Cherry and Shogren, 2008; Reinstein and Reiner, 2012; Carlsson, He and Martinsson, 2013). The second change to the experimental design was to tell participants what World Vision would spend the money on. In Study One they were simply told the money would go to World Vision; in Study Two subjects were told that World Vision would spend donations "to provide vaccinations to protect children in poor countries (e.g. in African countries like Rwanda, Tanzania and Uganda) against measles, whooping cough, diphtheria, hepatitis, polio and tetanus" and that "these diseases cause many children to die every year, but are easily preventable.” Brañas-Garza (2006) finds that providing subjects with information on what donations would be spent on increased donations. With the exception of these two changes, the experimental design was the same as in Study One (the Study Two instructions are included as Appendix 3). Subjects in the $N D-2$ treatment were able to make donations the following day between $8 \mathrm{am}$ and $5 \mathrm{pm}$, with subjects in the $N D W-2$ treatment being able to make a donation any weekday between 8am and 5pm starting the next day for the following week.

Our conjecture and hypothesis for Study Two are presented below.

Conjecture 5: giving subjects more time to donate will reduce donations. If donations are lower in $N D W$-2 this will provide evidence of an inertia effect.

\section{Hypothesis 5: $N D-2>N D W-2$}

Note, however, that in the absence of an inertia effect, donations could be higher in $N D W-2$ due to a lower effective transaction cost. Hence, failing to find a significant difference between $N D W$-2 and $N D$-2 does not necessarily mean there is no inertia effect as there could be both an inertia effect and a transaction cost effect, but with the two cancelling out. 


\section{Study Two Results}

Summary statistics for the two treatments are reported in Table 5, with the distribution of donations being shown in Figure $2{ }^{20}$ The first point to note is that donations are higher in the $N D$-2 treatment in Study Two (mean donation $=\$ 2.24$ ) than for the $N D$ treatment in Study One (mean donation $=\$ 1.20)$, meaning that the change in procedures successfully increased donations. Note from Figure 2 that for subjects choosing to make a donation, many gave the full \$10. Our key focus is on comparing the $N D-2$ and NDW-2 treatments. Both the number of positive donations and the mean donation are higher in $N D$-2, which is consistent with an inertia effect. However, these differences are not statistically significant. The t-test for the differences between means has a p-value of 0.672, the Wilcoxon Rank-Sum Test a p-value of 0.565 and the Fisher's Exact Test for the proportion of positive donations a p-value of 0.500. The differences between donations across treatments on the intensive margin are also statistically insignificant: the respective t-test and the Wilcoxon Rank-Sum Test p-values are 0.500 and 0.809 . In summary, we find some suggestive evidence of an inertia effect, but this is not statistically significant.

Result 5: There is no statistically significant evidence of inertia when the request is received at a time when the opportunity cost of time is high.

\footnotetext{
${ }^{20}$ One subject in the ND treatment donated the full $\$ 20$. As the instructions only asked subjects to give a maximum of $\$ 10$, we treat this as a $\$ 10$ donation for the purpose of reporting results. The full $\$ 20$, along with a matching subsidy of $\$ 20$, was forwarded to the charity.
} 
Table 5: Summary Statistics for Study Two

\begin{tabular}{|c|c|c|}
\hline Treatment & Next Day $(N D-2)$ & Next Day all Week (NDW-2) \\
\hline \multicolumn{3}{|c|}{ Panel A: All Data } \\
\hline Number of observations & 82 & 87 \\
\hline Average donation & 2.24 & 2.00 \\
\hline Median donation & 0 & 0 \\
\hline Standard deviation & 3.83 & 3.64 \\
\hline \multicolumn{3}{|c|}{ Panel B: Intensive Margin } \\
\hline Number of positive donations & $\begin{array}{c}26 \\
(31.7 \%)\end{array}$ & $\begin{array}{c}23 \\
(26.4 \%)\end{array}$ \\
\hline $\begin{array}{l}\text { Average donation conditional } \\
\text { on giving }\end{array}$ & 7.07 & 7.57 \\
\hline $\begin{array}{l}\text { Median donation conditional } \\
\text { on giving }\end{array}$ & 10 & 10 \\
\hline $\begin{array}{l}\text { Standard deviation } \\
\text { conditional on giving }\end{array}$ & 3.44 & 2.79 \\
\hline
\end{tabular}

Also of interest is how promptly people donated in the $N D W$-2 treatment. Of the twenty-three subjects who made a donation, thirteen donated on Day 1 (i.e. the day following the experimental session), three on Day 2, two on Day 3, one on Day 4 and five on Day 5. Hence, the majority of people donated on the first possible day, with the next most common response being to leave donating till the last possible day. It is possible that some of those who donated on the last day were prompted to do so by the looming deadline, and that they would not have donated if there had been no specified deadline for donations. 


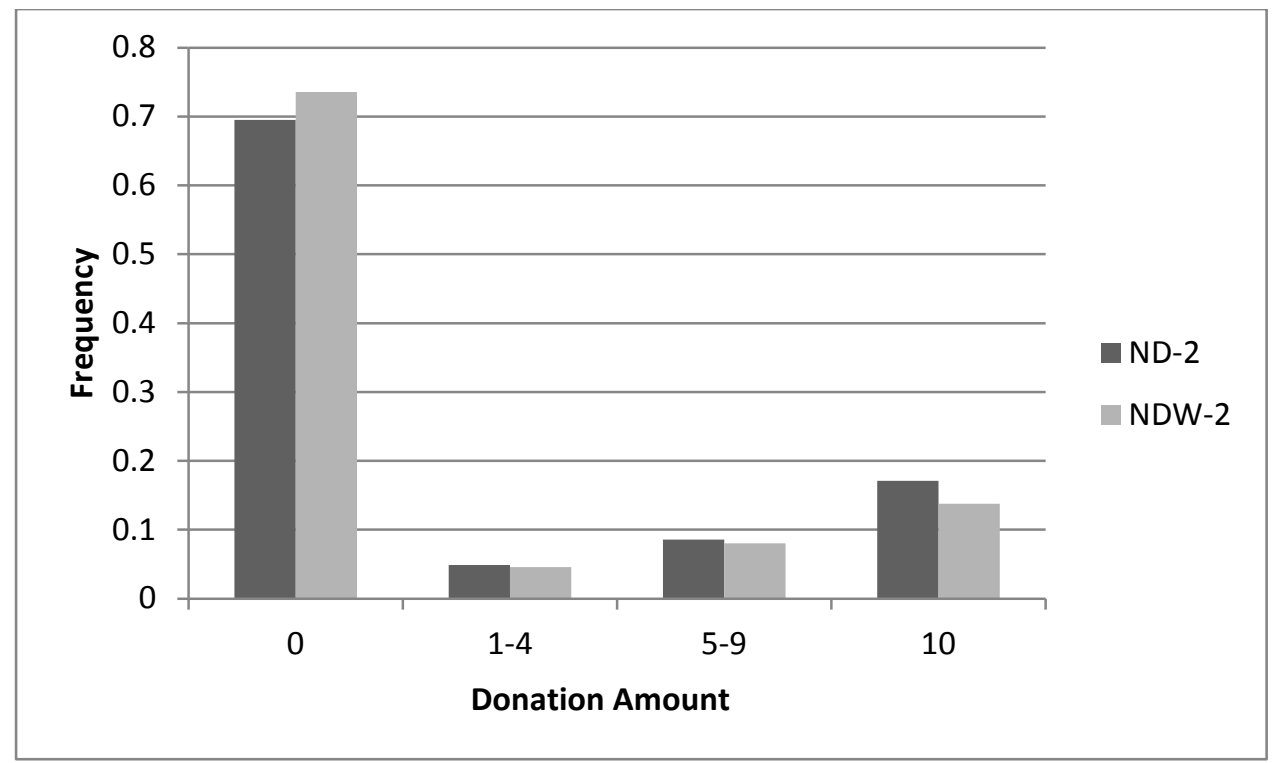

Figure 2: Frequency of Different Levels of Donations, Study Two

\section{Implications of Study Two Results}

We find donations are higher in $N D$-2, but this difference is not statistically significant. This does not mean there is no inertia effect, as it could be that any inertia effect is cancelled out by the effective transaction cost being lower in $N D W$-2. However, from a policy perspective, the important question is whether giving people more time to donate reduces donations, and we do not find statistically significant evidence that this is the case. It could be that the time horizon we considered was not long enough to detect inertia. One could hypothesize that if we had added a treatment where subjects had been given a month to donate, or if we included a treatment with no specific deadline, evidence of an inertia effect might have emerged. However, since it is not clear how long time horizon is required to induce inertia, we leave these explorations for future research.

\section{Conclusion}

This paper has analyzed three separate but closely related questions with respect to charitable giving. To what extent do transaction costs reduce charitable giving? Does this depend on how busy potential donors are when the solicitation is received? Do people suffer from inertia with respect to charitable giving? We analyze these three questions using a Dictator Game experiment where the recipient is a charity. A transaction cost is introduced by having 
subjects who wish to donate place their donation in a secure box located a short walk away. This transaction cost significantly reduces donations, especially small donations, compared to a baseline with no transaction cost. We control for the opportunity cost of time, at the time of the solicitation, by giving some subjects the opportunity of walking to the donation box during time they planned to be taking part in the experiment, whereas other subjects do not have this option. We find that donations are lower when the opportunity cost of time is high at the time of the solicitation. We test for inertia by giving some subjects longer to donate than others. In Study One, consistent with our hypothesis, there is no evidence of inertia when the opportunity cost of time is low at the time of the solicitation. In Study Two, we find some evidence that giving subjects longer to donate reduces donations, but this difference is not statistically significant. This does not mean that there is no inertia effect, as it could be that inertia is cancelled out by the effective transaction cost being lower when subjects are given more time to donate. However, from a policy perspective, the important question is whether giving people more time to donate reduces donations and we fail to find statistically significant evidence that this is the case.

Our results have two important policy implications. The first is that charities should use solicitation techniques which minimize transaction costs for potential donors, especially if the charity finds it valuable to receive small donations. Encouraging more use of the push pay app, and text messaging as a means of making donations, are examples of how transaction costs can be minimized. Our second key policy implication is that it is important to solicit donations when people are likely to not be too busy. Street collections would be an example where the transaction costs are low. While passers-by might be too busy to donate, people waiting at a bus stop are likely not. 


\section{References}

Bekkers, R. (2007) "Measuring altruistic behaviour in surveys: the all-or-nothing dictator game”, Survey Research Methods 1: 139-144.

Burger, N., G. Charness, and J. Lynham (2011) “Field and online experiments on procrastination and willpower”, Journal of Economic Behavior and Organization 77: 393404.

Brañas-Garza, P. (2006) "Poverty in dictator games: awakening solidarity,” Journal of Economic Behavior and Organization, 60:306-320.

Breman, A. (2011) “Give more tomorrow: Two field experiments on altruism and intertemporal choice”, Journal of Public Economics 95: 1349-1357.

Carlsson, F., H. Haoran and P. Martinsson (2013) "Easy come, easy go: The role of windfall money in lab and field experiments”, Experimental Economics 16: 190-207.

Cherry, T., P. Frykblom and J. Shogren (2002) “Hardnose the dictator”, American Economic Review 92: 1218-1221.

Cherry, T. and J. Shogren (2008) "Self-interest, sympathy and the origins of endowments”, Economics Letters 101, 69-72.

Choi, J.C., D. Laibson, B. Madrian and A. Metrick (2002) “Defined contribution pensions: plan rules, participant decisions, and the path of least resistance” in Tax Policy and the Economy, vol 16 (ed. J. Poterba), Cambridge, Masachusetts: MIT Press: 67-113.

Davis, D.D. (2006) “Rebate subsidies, matching subsidies and isolation effects”, Judgement and Decision Making 1: 13-22.

Dekel, E. and B. Lipman (2011) “Costly self control and random self indulgence”, unpublished manuscript.

de Oliveira, A.C.M., R.T.A. Croson and C. Eckel (2011) “The giving type: identifying donors”, Journal of Public Economics 95: 428-435.

Eckel, C.C. and P.J. Grossman (1996) “Altruism in anonymous dictator games”, Games and Economic Behavior 16:181-191. 
Eckel, C.C. and P. J. Grossman (2003) "Rebate versus matching: does how we subsidize charitable contributions matter?” Journal of Public Economics 87: 681-701.

Etang, A., D. Fielding and S. Knowles (2012) “Giving to Africa and Perceptions of Poverty”, Journal of Economic Psychology 33: 819-832.

Fong, C.M. and E.F.P. Luttmer (2011) "Do fairness and race matter in generosity? Evidence from a nationally representative charity experiment”, Journal of Public Economics 95:372394.

Fudenberg, D. and D.K. Levine (2006) “A dual-self model of impulse control”, American Economic Review 96: 1449-1476.

Greiner, B. (2004) “An online recruitment system for economic experiments” in Forschung und wissenschaftliches Rechnen 2003. GWDG Bericht 63, Göttingen : Ges. für Wiss. Datenverarbeitung Kurt Kremer, (ed. V Macho): 79-93.

Halevy, Y. (2008) "Strotz meets Allais: Diminishing impatience and the certainty effect”, American Economic Review 98: 1145-1162.

Handel, B.R. (2013) “Adverse selection and inertia in health insurance markets: When nudging hurts”, American Economic Review 103: 2643-2682.

Harris C, and D. Laibson (2013) “Instantaneous gratification”, Quarterly Journal of Economics 128:205-248.

Huck, S. and I. Rasul (2010) “Transactions costs in charitable giving” Evidence from two field experiments”, The B. E. Journal of Economic Analysis and Policy (Advances), 10: article 31 .

Karlan, D. and M. A. McConnell (2012) "Hey look at me: the effect of giving circles on giving”, NBER Working Paper 17737.

Landry, C.E., A. Lange, J.A. List, M.K. Price and N.G. Rupp (2006) “Toward an understanding of the economics of charity: evidence from a field experiment”, Quarterly Journal of Economics 121:747-782. 
Leventhal, H., R. Singer and S. Jones (1965) “Effects of fear and specificity on recommendation upon attitudes and behavior”, Journal of Personality and Social Psychology 2: 20-29.

List, J.A. and D. Lucking-Reiley (2002) “The effects of seed money and refunds on charitable giving: experimental evidence from a university capital campaign”, Journal of Political Economy 110: 215-233.

Martinsson, P., K. Myrseth and C. Wollbrant (2012) “Reconciling pro-social vs. selfish behavior: On the role of self-control”, Judgment and Decision Making 7: 304-315.

Meer, J. and O. Rigbi (2013) "The effects of transaction costs and social distance: Evidence from a field experiment”, The B.E. Journal of Economic Analysis and Policy (Contributions) 13: $271-296$.

Null, C. (2011) “Warm glow, information, and inefficient charitable giving”, Journal of Public Economics 95: 455-465.

O’Donoghue, T. and M. Rabin (1999) “Doing it now or later”, American Economic Review, 89: 103-124.

Orman, T. (2004) The Real Story on Trout Fishing in New Zealand, Spring Creek Publishing, Marlborough New Zealand.

Ozdenoren, E., S. Salant and D. Silverman (2012) "Willpower and the optimal control of visceral urges”, Journal of the European Economic Association, 10: 342-368.

Reinstein, D. and G. Riener (2012) “Decomposing desert and tangibility effects in a charitable giving experiment”, Experimental Economics 15: 229-40.

Samuelson, W. and R.J. Zeckhauser (1988) “Status quo bias in decision making”, Journal of Risk and Uncertainty 1: 7-59.

Smith, A. (2012) “Real time charitable giving: Why mobile phone users texted millions of dollars in aid to Haiti earthquake relief and how they got their friends to do the same”, Pew Research Center's Internet \& American Life Project Report (available online at http://www.pewinternet.org/ /media//Files/Reports/2012/Real\%20Time\%20Charitable\%20G iving.pdf). 
Small, D.A., G. Loewenstein and P. Slovic (2007) "Sympathy and callousness: the impact of deliberative thought on donations to identifiable and statistical victims," Organizational Behaviour and Human Decision Processes 102, 143-153.

Van Diepen, M., B. Donkers and P. H. Franses (2009) "Dynamic and competitive effects of direct mailings: a charitable giving application”, Journal of Marketing Research 46:120-133. 


\section{APPENDICES: FOR ONLINE PUBLICATION}

\section{Appendix 1: Survey Completed by Subjects in Study One}

\section{Survey: Life as a Student}

This survey asks questions about yourself, some questions about student life and some general knowledge questions about the University and Christchurch. Your responses to the questions will be completely anonymous. No one, including the researchers, will ever know which individuals gave which answers.

Some questions about yourself

1. Gender: Male

Female

2. Intended major subject (if known)

3. Are you an active member of any voluntary organisation or club (e.g., sports, craft, social club)? Yes $\bigcirc \square \quad$ No $\bigcirc$ If yes, specify what sort of organisation/club

4. How frequently do you take part in organised religious activities? once a week or more $\bigcirc \quad$ less than once a week but more than once a month once a month or less $\bigcirc \square$ never or almost never

5. How often do you follow news from around the world (e.g., through television, the internet or newspapers)?

most days

2-3 times a week

once a week $\bigcirc$ less than once a week

6. How often do you follow news from New Zealand (e.g., through television, the internet or newspapers)?

most days

once a week $\bigcirc$

\section{2-3 times a week}

less than once a week 
7. If you do follow news, from around the world or from New Zealand, which media do you use the most often?

internet $\bigcirc \square$ television $\bigcirc \square$ newspaper $\bigcirc \quad$ other $\bigcirc \square$

don't follow world news

8. How often do you watch sport on television?

several times a week $\bigcirc \square \quad$ once or twice a week

between once a week and once a month $\bigcirc \square$ never $\bigcirc$

9. If you do watch sport on television, which sports do you watch

10. In an average week, how many nights do you spend out at a bar, club, restaurant or cinema?

6-7 $\bigcirc \square \quad 3-5 \bigcirc \square \quad 1-2 \bigcirc \square \quad$ zero

Some questions about student life and the University of Canterbury

11. What is the main reason you chose to study at Canterbury rather than at another university?

Academic reputation of Canterbury

Social life at Canterbury

Family/friends in Christchurch

Other

If other, please specify

12. For how many years are you planning on studying at Canterbury?
1
2
3
4 or more

13. Where do you live?

Hall of residence $\bigcirc \square \quad$ Private flat

Family home

Other 
14. Do you have a student loan?

Yes $\bigcirc \square \quad$ No

15. Do your parents contribute to your fees or living expenses?

Yes $\bigcirc \square \quad$ No

16. Who is the current Vice Chancellor of the University of Canterbury?

17. In what year did the University of Canterbury open?

Some general knowledge questions about Christchurch and the surrounding area:

18. Who is the current mayor of Christchurch?

19. The city of Christchurch is named after a college at which English university?

20. In December 1850, 4 ships carrying settlers from England arrived in Lyttelton . Name one of the ships.

21. Who is the current coach of the Crusaders?

22. In the 2006 census, the percentage of people living in Christchurch who listed their ethnicity as European was:

$95 \% \bigcirc \square \quad 85 \% \bigcirc \square \quad 75 \% \bigcirc \square \quad 65 \%$ 


\section{Appendix 2: Study One Instructions}

[The survey instructions shown below were identical across all treatments in Study One.]

\section{Instructions: Survey}

Thank you for participating in this research project. As well as completing a survey, we will also get you to take part in a short decision-making task. This should take no longer than 1 hour.

\section{Survey}

The survey form is in a manila envelope which we will now hand out to you. You may start filling in the survey once it is handed to you, and we will give you ten minutes to complete this. Your anonymity is guaranteed as you have not been asked to write your name or ID number on the survey. We will get you to place your completed survey in the manila envelope when you hand it back in, so we cannot see your answers. Please do not leave when you finish the survey as we still have the decision-making task to conduct.

[The decision-making task instructions shown below are those used in Baseline.]

\section{Instructions: Decision-making task}

\section{White envelope}

We are going to hand out a white envelope containing your \$20 payment for filling out the survey. Please open the envelope and confirm it contains $\$ 20$. We will get you to sign a receipt for this before you leave.

\section{Decision-making task}

We are now going to undertake the second part of this session. We ask that you listen quietly to the following instructions and do not speak until you have left the room.

\section{Donation}

We would now like to give you the opportunity, if you wish, to donate some, or all, of your \$20 payment to World Vision New Zealand, who are a registered charity doing development 
work in poor countries overseas. Any money you choose to donate to World Vision will be matched by us dollar for dollar (in other words, we will double your donation) and we will forward all money directly to World Vision. The white envelope you opened earlier contains a \$10 note, a \$5 note, two \$2 coins and a \$1 coin, so it is possible to donate any whole dollar amount, between $\$ 0$ and $\$ 20$ to World Vision. You are under no obligation to donate any money to World Vision unless you wish to do so.

\section{Anonymity}

Your decision is completely anonymous. This task is designed in such a way that no-one will ever know how much any individual has given. Your privacy is guaranteed because neither your name nor your student ID number will appear on any form that records your decisions. The only identifying mark in all records will be the alpha-numeric code on your form and envelopes. We have no way of knowing who has been assigned which code. We will shortly invite you to put any money you wish to donate in a blue envelope and place this envelope in a box outside the lab when you leave. As you are sitting in a cubicle, no-one, including us, can see how much money you put in the blue envelope.

\section{Blue envelope}

We are also going to hand out a blue envelope containing a blue form with a space to indicate how much money, if any, you wish to give to World Vision, and how much money this means World Vision will receive once we have matched your donation dollar for dollar. For audit reasons, we are only able to match any donation you make dollar for dollar if we have a written record of what has been donated, hence the need for you to complete this form.

Please open the blue envelope and take a few seconds to decide how much, if anything, you want to donate to World Vision. Please complete the blue form, and place the form, and any money you have chosen to donate, in the blue envelope and seal the envelope. We suggest you put any money you have decided to keep in your pocket or bag. We will give you two minutes to do this.

\section{Receipt}

At the end of the session we will ask you one at a time to come up to the room at the back of the lab and sign a form acknowledging that you were paid \$20 for completing the survey. When you have done this, please leave the lab and place the blue envelope, whether you have chosen to donate any money or not, in the red box labelled "Economics" sitting outside the lab. Please do not wait around outside the lab once you have done this. 
Thank you once more for taking part in our study.

[The decision-making task instructions shown below are those used in $1 \mathrm{H}$ ]

\section{Instructions: Decision-making task}

\section{White envelope}

We are going to hand out a white envelope containing your \$20 payment for filling out the survey. Please open the envelope and confirm it contains $\$ 20$. We will get you to sign a receipt for this before you leave.

\section{Decision-making task}

We are now going to undertake the second part of this session. We ask that you listen quietly to the following instructions and do not speak until you have left the room.

\section{Donation}

We would now like to give you the opportunity, if you wish, to donate some, or all, of your \$20 payment to World Vision New Zealand, who are a registered charity doing development work in poor countries overseas. Any money you choose to donate to World Vision will be matched by us dollar for dollar (in other words, we will double your donation) and we will forward all money directly to World Vision. The white envelope you opened earlier contains a \$10 note, a \$5 note, two \$2 coins and a \$1 coin, so it is possible to donate any whole dollar amount, between $\$ 0$ and $\$ 20$ to World Vision. You are under no obligation to donate any money to World Vision unless you wish to do so.

\section{Anonymity}

Your decision is completely anonymous. This task is designed in such a way that no-one will ever know how much any individual has given. Your privacy is guaranteed because neither your name nor your student ID number will appear on any form that records your decisions. The only identifying mark in all records will be the alpha-numeric code on your form and envelopes. We have no way of knowing who has been assigned which code. We will shortly invite you to put any money you wish to donate in a blue envelope and place this envelope in a box labelled "ECON" located on the ground floor in the main entrance of the Psychology building (the car park side, not the Cafe 101 side) following this session. You will have until [insert 
time] today to place the envelope in the box if you wish to make a donation. Note that the box will be emptied shortly after [insert time] today, so you cannot make a donation after that time, even if you see the box there. There is a map in the blue envelope showing the location of the Psychology Building.

\section{Blue envelope}

We are also going to hand out a blue envelope containing a blue form with a space to indicate how much money, if any, you wish to give to World Vision, and how much money this means World Vision will receive once we have matched your donation dollar for dollar. For audit reasons, we are only able to match any donation you make dollar for dollar if we have a written record of what has been donated, hence the need for you to complete this form.

Please open the blue envelope and check that it contains a map and the blue form. However, please do not fill in the blue form until you have left the lab. If you need a pen to fill it in, feel free to take the one we lent you earlier. Remember if you choose to make a donation, you need to place the envelope, containing your donation and the completed blue form, in the red box in the Psychology Building by 3pm today.

\section{Receipt}

At the end of the session we will ask you one at a time to come up to the room at the back of the lab and sign a form acknowledging that you were paid \$20 for completing the survey. When you have done this, please leave the lab and do not wait around outside. Remember if you wish to make a donation you have until [insert time] today to do so.

Thank you once more for taking part in our study.

[The decision-making task instructions shown below are those used in 1D]

\section{Instructions: Decision-making task}

\section{White envelope}

We are going to hand out a white envelope containing your \$20 payment for filling out the survey. Please open the envelope and confirm it contains $\$ 20$. We will get you to sign a receipt for this before you leave. 


\section{Decision-making task}

We are now going to undertake the second part of this session. We ask that you listen quietly to the following instructions and do not speak until you have left the room.

\section{Donation}

We would now like to give you the opportunity, if you wish, to donate some, or all, of your \$20 payment to World Vision New Zealand, who are a registered charity doing development work in poor countries overseas. Any money you choose to donate to World Vision will be matched by us dollar for dollar (in other words, we will double your donation) and we will forward all money directly to World Vision. The white envelope contains a \$10 note, a \$5 note, two \$2 coins and a \$1 coin, so it is possible to donate any whole dollar amount, between $\$ 0$ and $\$ 20$ to World Vision. You are under no obligation to donate any money to World Vision unless you wish to do so.

\section{Anonymity}

Your decision is completely anonymous. This task is designed in such a way that no-one will ever know how much any individual has given. Your privacy is guaranteed because neither your name nor your student ID number will appear on any form that records your decisions. The only identifying mark in all records will be the alpha-numeric code on your form and envelopes. We have no way of knowing who has been assigned which code.

\section{Blue envelope}

We are also going to hand out a blue envelope containing a blue form with a space to indicate how much money, if any, you wish to give to World Vision, and how much money this means World Vision will receive once we have matched your donation dollar for dollar. For audit reasons, we are only able to match any donation you make dollar for dollar if we have a written record of what has been donated, hence the need for you to complete this form.

Please do not open the blue envelope until you have left the lab. If you wish to make a donation put the money you wish to donate in the blue envelope and place this envelope in a box labelled "ECON" located on the ground floor in the main entrance of the Psychology building (the car park side, not the Cafe 101 side) tomorrow. You will have from 8am until 5pm tomorrow ([insert day of week and date]) to place the envelope in the box if you wish to make a donation. Note that donations will only be matched dollar for dollar if placed in the box between 8am and 5pm tomorrow. There is a map in the blue envelope showing the location of the Psychology Building. 
Remember if you choose to make a donation, you need to place the envelope, containing your donation and the completed blue form, in the red box in the Psychology Building between 8am and 5pm tomorrow ([insert day of week and date]).

\section{Receipt}

At the end of the session we will ask you one at a time to come up to the room at the back of the lab and sign a form acknowledging that you were paid \$20 for completing the survey. When you have done this, please leave the lab and do not wait around outside. Remember if you wish to make a donation you can do this between 8am and 5pm tomorrow.

Thank you once more for taking part in our study.

[The decision-making task instructions shown below are those used in $N D$ ]

\section{Instructions: Decision-making task}

\section{White envelope}

We are going to hand out a white envelope containing your \$20 payment for filling out the survey. Please open the envelope and confirm it contains $\$ 20$. We will get you to sign a receipt for this before you leave.

\section{Decision-making task}

We are now going to undertake the second part of this session. We ask that you listen quietly to the following instructions and do not speak until you have left the room.

\section{Donation}

We would now like to give you the opportunity, if you wish, to donate some, or all, of your \$20 payment to World Vision New Zealand, who are a registered charity doing development work in poor countries overseas. Any money you choose to donate to World Vision will be matched by us dollar for dollar (in other words, we will double your donation) and we will forward all money directly to World Vision. The white envelope contains a \$10 note, a \$5 note, two $\$ 2$ coins and a $\$ 1$ coin, so it is possible to donate any whole dollar amount, between 
\$0 and \$20 to World Vision. You are under no obligation to donate any money to World Vision unless you wish to do so.

\section{Anonymity}

Your decision is completely anonymous. This task is designed in such a way that no-one will ever know how much any individual has given. Your privacy is guaranteed because neither your name nor your student ID number will appear on any form that records your decisions. The only identifying mark in all records will be the alpha-numeric code on your form and envelopes. We have no way of knowing who has been assigned which code.

\section{Blue envelope}

We are also going to hand out a blue envelope containing a blue form with a space to indicate how much money, if any, you wish to give to World Vision, and how much money this means World Vision will receive once we have matched your donation dollar for dollar. For audit reasons, we are only able to match any donation you make dollar for dollar if we have a written record of what has been donated, hence the need for you to complete this form.

Please do not open the blue envelope until you have left the lab. If you wish to make a donation put the money you wish to donate in the blue envelope and place this envelope in a box labelled "ECON" located on the ground floor in the main entrance of the Psychology building (the car park side, not the Cafe 101 side) tomorrow. You will have from 8am until 5pm tomorrow ([insert day of week and date]) to place the envelope in the box if you wish to make a donation. Note that donations will only be matched dollar for dollar if placed in the box between 8am and 5pm tomorrow. There is a map in the blue envelope showing the location of the Psychology Building.

Remember if you choose to make a donation, you need to place the envelope, containing your donation and the completed blue form, in the red box in the Psychology Building between 8am and 5pm tomorrow ([insert day of week and date]).

\section{Receipt}

At the end of the session we will ask you one at a time to come up to the room at the back of the lab and sign a form acknowledging that you were paid \$20 for completing the survey. When you have done this, please leave the lab and do not wait around outside. Remember if you wish to make a donation you can do this between 8am and 5pm tomorrow.

Thank you once more for taking part in our study. 


\section{Appendix Three: Study Two Instructions}

[The instructions below are for $N D-2]$

\section{Instructions: Decision-making task}

Thank you for participating in this research project, which should take no longer than 30 minutes.

\section{Show up fee}

You have all received your $\$ 10$ show up fee when you arrived at the lab. We will get you to sign a receipt for this before you leave.

\section{Decision-making task}

We are now going to undertake the decision making task. We ask that you listen quietly to the following instructions and do not speak until you have left the lab. If you have a question after we finish reading the instructions, please raise your hand and the experimenter will approach you and answer your question in private.

\section{Donation}

We will shortly hand out to you a brown envelope containing $\$ 10$. This money is being given to you in addition to your \$10 show up fee. You can either keep this additional \$10 for yourself, or donate some, or all, of it to World Vision New Zealand, who are a registered charity doing development work in poor countries overseas. Any money you choose to donate to World Vision will be matched by us dollar for dollar (in other words, we will double your donation) and we will forward all money directly to World Vision. World Vision will use this money to provide vaccinations to protect children in poor countries (e.g. in African countries like Rwanda, Tanzania and Uganda) against measles, whooping cough, diphtheria, hepatitis, polio and tetanus. These diseases cause many children to die every year, but are easily preventable. The brown envelope contains a \$5 note, two \$2 coins and a \$1 coin, so it is possible to donate any whole dollar amount, between $\$ 0$ and $\$ 10$ to World Vision. You are under no obligation to donate any money to World Vision unless you wish to do so. 


\section{Anonymity}

Your decision is completely anonymous. This task is designed in such a way that no-one will ever know how much any individual has given. Your privacy is guaranteed because neither your name nor your student ID number will appear on any form that records your decisions. The only identifying mark in all records will be the alpha-numeric code on your form and envelope. We have no way of knowing who has been assigned which code.

\section{Blue envelope}

We are also going to hand out a blue envelope containing a blue form with a space to indicate how much money, if any, you wish to give to World Vision, and how much money this means World Vision will receive once we have matched your donation dollar for dollar. For audit reasons, we are only able to match any donation you make dollar for dollar if we have a written record of what has been donated, hence the need for you to complete this form.

If you wish to make a donation put the money you wish to donate in the blue envelope and place this envelope in the box labelled "ECON" located on the ground floor in the main entrance of the Psychology building (the car park side, not the Cafe 101 side) tomorrow. You will have from 8am until 5pm tomorrow ([insert day of week and date]) to place the envelope in the box if you wish to make a donation. Note that donations will only be matched dollar for dollar if placed in the box between 8am and 5pm tomorrow. There is a map in the blue envelope showing the location of the Psychology Building.

Remember if you choose to make a donation, you need to place the blue envelope, containing your donation and the completed blue form, in the red box in the Psychology Building between 8am and 5pm tomorrow ([insert day of week and date]).

\section{Receipt}

At the end of the session we will ask you one at a time to come up to the room at the back of the lab and sign a form acknowledging that you were paid \$20 (the \$10 show up fee and the additional \$10). When you have done this, please leave the lab and do not wait around outside. Remember if you wish to make a donation you can do this between 8am and 5pm tomorrow. Thank you once more for taking part in our study. 
[The instructions below are for $N D-2$ ]

\section{Instructions: Decision-making task}

Thank you for participating in this research project, which should take no longer than 30 minutes.

\section{Show up fee}

You have all received your $\$ 10$ show up fee when you arrived at the lab. We will get you to sign a receipt for this before you leave.

\section{Decision-making task}

We are now going to undertake the decision making task. We ask that you listen quietly to the following instructions and do not speak until you have left the lab. If you have a question after we finish reading the instructions, please raise your hand and the experimenter will approach you and answer your question in private.

\section{Donation}

We will shortly hand out to you a brown envelope containing $\$ 10$. This money is being given to you in addition to your $\$ 10$ show up fee. You can either keep this additional \$10 for yourself, or donate some, or all, of it to World Vision New Zealand, who are a registered charity doing development work in poor countries overseas. Any money you choose to donate to World Vision will be matched by us dollar for dollar (in other words, we will double your donation) and we will forward all money directly to World Vision. World Vision will use this money to provide vaccinations to protect children in poor countries (e.g. in African countries like Rwanda, Tanzania and Uganda) against measles, whooping cough, diphtheria, hepatitis, polio and tetanus. These diseases cause many children to die every year, but are easily preventable. The brown envelope contains a \$5 note, two \$2 coins and a \$1 coin, so it is possible to donate any whole dollar amount, between $\$ 0$ and $\$ 10$ to World Vision. You are under no obligation to donate any money to World Vision unless you wish to do so.

\section{Anonymity}

Your decision is completely anonymous. This task is designed in such a way that no-one will ever know how much any individual has given. Your privacy is guaranteed because neither 
your name nor your student ID number will appear on any form that records your decisions. The only identifying mark in all records will be the alpha-numeric code on your form and envelope. We have no way of knowing who has been assigned which code.

\section{Blue envelope}

We are also going to hand out a blue envelope containing a blue form with a space to indicate how much money, if any, you wish to give to World Vision, and how much money this means World Vision will receive once we have matched your donation dollar for dollar. For audit reasons, we are only able to match any donation you make dollar for dollar if we have a written record of what has been donated, hence the need for you to complete this form.

If you wish to make a donation put the money you wish to donate in the blue envelope and place this envelope in the box labelled "ECON" located on the ground floor in the main entrance of the Psychology building (the car park side, not the Cafe 101 side.) You will have from 8am tomorrow ([insert day of week and date]) until 5pm [insert day of week and date] to place the envelope in the box if you wish to make a donation. Please note that you may place the envelope in the box any workday as the building will closed on Saturday and Sunday. Note that donations will only be matched dollar for dollar if placed in the box between $8 \mathrm{am}$ and 5pm from tomorrow for the next week. There is a map in the blue envelope showing the location of the Psychology Building.

Remember if you choose to make a donation, you need to place the blue envelope, containing your donation and the completed blue form, in the red box in the Psychology Building between 8am and 5pm from tomorrow ([insert day of week and date]) until [insert day of week and date].

\section{Receipt}

At the end of the session we will ask you one at a time to come up to the room at the back of the lab and sign a form acknowledging that you were paid \$20 (the \$10 show up fee and the additional \$10). When you have done this, please leave the lab and do not wait around outside. Remember if you wish to make a donation you can do this between 8am and 5pm from tomorrow until [insert day of week] next week. Thank you once more for taking part in our study. 